\title{
INTERCHANGE NODES BETWEEN SUBURBAN AND URBAN PUBLIC TRANSPORT: A CASE STUDY OF THE CZECH REPUBLIC
}

Igor Ivan

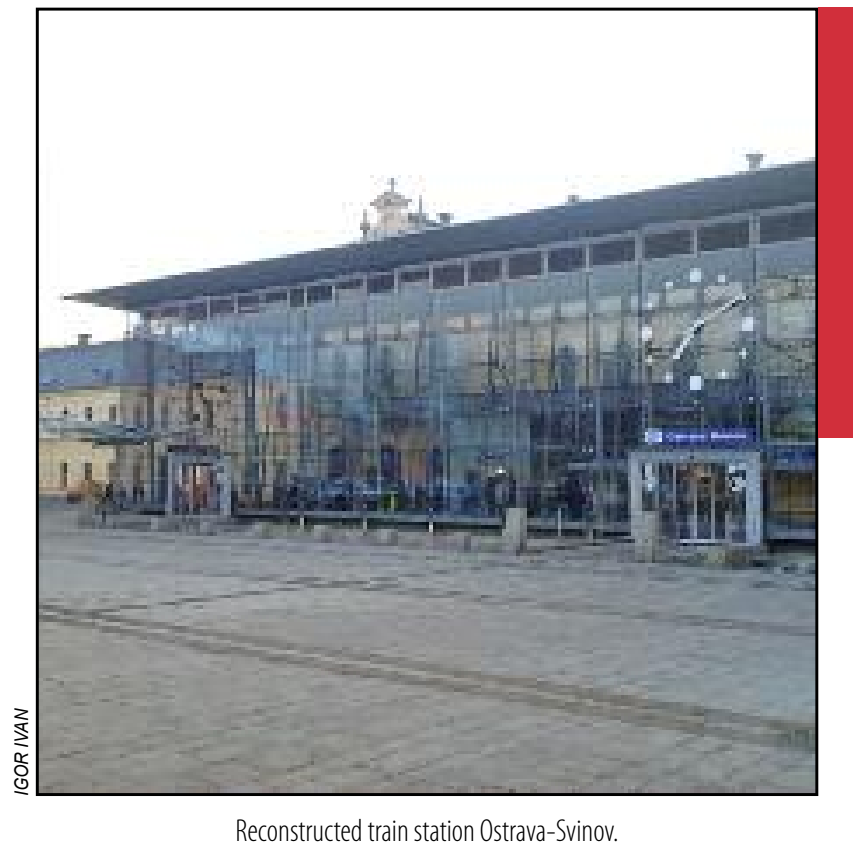




\section{Interchange nodes between suburban and urban public transport: A case study of the Czech Republic}

DOI: http://dx.doi.org/10.3986/AGS.754

UDC: 911.375:656(437.3)

COBISS: 1.01

ABSTRACT: This paper presents a methodology for localizing theoretical interchange nodes used for interchange between suburban and urban public transport in thirteen regional capitals in the Czech Republic. This methodology is based on the use of current timetables and simulation of more than 2,500 public transport connections between selected surrounding municipalities with significant commuter flows and randomly selected urban public transport stops within the regional capitals. The second part of the paper focuses on particular interchange nodes. Regional capitals are divided into groups according to the level of centrality of interchange nodes and the prevailing orientation of the transport mode. The article also analyzes the time stability of localized interchange nodes.

KEY WORDS: geography, urban transport, suburban transport, public transport, commuting, interchange, stop, Czech Republic

The article was submitted for publication on February $2^{\text {nd }}, 2014$.

ADDRESS:

Igor Ivan

Institute of geoinformatics, Technical university of Ostrava

17. listopadu 15, 70800, Ostrava, Czech Republic

E-mail: igor.ivan@vsb.cz 


\section{Introduction}

The decision of mode choice remains a crucial issue in studying transport geography. Although some cities or even countries have been successful in shifting car users onto public transport, others are struggling despite their efforts to make public transport more attractive. Many relevant factors influencing the final decision have been identified, but two of them are the most important: the travel time and the level of variability of travel time (van Vugt, van Lange and Meertens 1996). Unlike price and other factors, time spent traveling is an absolute constraint that cannot be increased infinitely (Vande Walle and Steenberghen 2006). Travel time is not uniform, but consists of several phases: preparation time for a journey, walking and waiting time, time needed for interchanges, and in-vehicle time. All of these times are perceived differently by individual passengers. In addition, passengers are more sensitive to out-of-vehicle time than in-vehicle time (1.5 to 2.3 times more; Vande Walle and Steenberghen 2006). The phases of out-vehicle time are quite variable. The time needed for preparing varies according to the length, purpose, and frequency of the journey. Walking and waiting time are mostly perceived negatively (except for very long journeys), and in the case of commuting using suburban public transport (SPT) walking time can make up 24 to $30 \%$ of the time of the entire journey in the Czech Republic (Ivan 2010). Changes of transport vehicles or transport modes are generally perceived negatively. Only a few empirical studies have tried to quantify the weights for particular out-vehicle times. Vande Walle and Steenberghen (2006) provided a general overview of these studies, and the Flemish multimodal transport model is considered to be the most complex one. This model provides weights for each out-vehicle time; one minute of waiting time is weighted by $165 \%$, each minute of walking time by $150 \%$, and for each change of vehicle an extra factor is added between 2 and 15 minutes, depending on the characteristics of the interchange.

Vehicle or transport mode interchange is a fundamental issue. On the one hand, passengers in multimodal transport systems often have to change their transport mode to reach their destinations, and the interchange can significantly expand the accessible area. On the other hand, this has a significant impact on the demand for the public transport and reduces its competitiveness because interchange has a cost, which can often be quite considerable. The process of urban sprawl and reorganization of public transport planning in most cities makes interchange one of the crucial problems of public transport. Based on a study by Guo and Wilson (2011) comparing the situation in several cities, about $70 \%$ of underground trips and $30 \%$ of bus trips involve at least one interchange in London, and $70 \%$ and $40 \%$ of all public transport trips include one or more interchanges in Munich and Paris. Bole et al. (2012) also noted that the role of train and bus transport should be increased and connected to urban public transport (UPT) at primary interchange nodes in the case of Ljubljana.

The interchange nodes can be developed in places where two or more public transport links or transport modes cross or approach. The most important requirement for the interchange nodes from the public transport operators' point of view is securing passengers' maximum safety and comfort. The most important requirement from the passengers' point of view is the time needed to carry out the interchange; they prefer a short, one-level transfer. It is important to minimize the distance and time connected changing between transport vehicles; quick and easy interchange is essential. Based on the results from thirty-two in-depth interviews conducted with public transport users in Scotland, several factors associated with poor quality of interchanges have been selected (Hine and Scott 2000). Common complains relate to poor quality of the waiting environment, paying for toilet facilities and their poor standards, poor timetables, personal security, poor signage within the interchange node, and long distances between different interchange nodes. Similar results have also been reported by Wardman et al. (2001). Nevertheless, for passengers an interchange is mainly considered a potential cause of delay (Stokes 1994). In general, participants in the in-depth interview study sought to avoid interchanges (especially during commuting and similar time-sensitive trips).

The issue of interchange is often overlooked by public transport planning agencies, although they are often aware of the importance of convenient interchanges. Based on the results of a survey conducted in twenty European cities by the European Commission, many operators did not know the volume of interchanges taking place in their systems. They have explained this disinterest by the impact of several factors: organizational barriers, the fact that interchanges cannot be completely eliminated by transfer planning improvements towards seamless travel, and lack of analytical tools to understand interchange behaviour (GUIDE 1999).

This paper reports the findings of an analysis of interchange nodes in thirteen regional capitals (NUTS3) in the Czech Republic. The goal of this paper is to select several main interchange nodes (stops, stations) 
from current stops within these cities based on current timetables and proposed methodology to determine whether they play the role of interchange node during the entire day, and to determine the main public transport mode orientation of regional capitals. For this paper, an interchange node is defined as a public transport stop used for changing between SPT and UPT.

\section{Methodology of interchange node localization}

The approach for localizing interchange nodes used in this study was based on real transport connections offered by current timetables. This study does not calculate real flows of passengers. This methodology involves searching hundreds of public transport connections between defined places of origin and destination in thirteen regional capitals. The hypothesis is that a public transport stop is considered an interchange node if it is suggested by timetables several times as the stop to change the transport vehicle (mode) from SPT to UPT.

\subsection{Origins: surrounding municipalities}

The municipalities of origin for commuting by public transport were defined by a set of ten municipalities surrounding each of the regional capital within 100 kilometers (as the crow flies). Two important factors

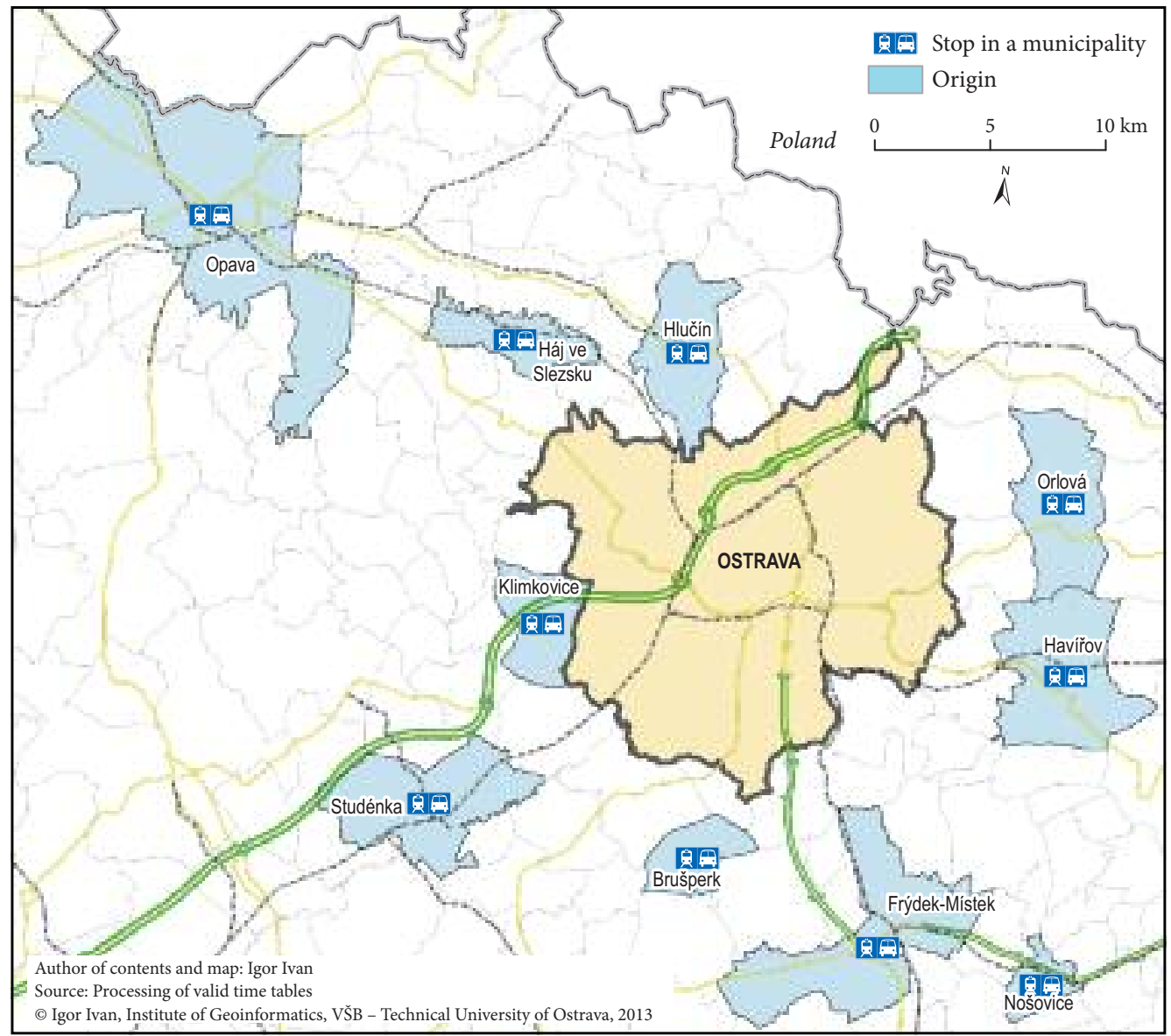

Figure 1: Surrounding municipalities of the origin: the case of Ostrava. 
were considered for selecting these 130 municipalities. Significant and stable commuting flows between each municipality and the capital must exist according to the results of the 1980, 1991, and 2001 censuses. The second condition ensures the spatial distribution of these municipalities around the regional capital to include possible commuting flows from all directions (Figure 1).

\subsection{Destinations: randomly selected stops in regional capitals}

Randomly selected UPT stops played the role of destinations. The count of these stops differs from city to city because of their sizes. The maximum number of UPT stops was selected in Prague, where one randomly selected UPT stop defines each part of the city, and so destinations in Prague are ultimately defined by fifty-seven UPT stops. The second- and third-largest cities (Brno and Ostrava) are each defined by fifty UPT stops, even though the number of city districts is halved and each city district contains at least one UPT stop. In the case of the other ten smaller regional capitals, $1 \%$ of all UPT stops within the city were selected, but at least ten UPT stops. Altogether, 268 UPT stops were randomly selected in all thirteen regional capitals.

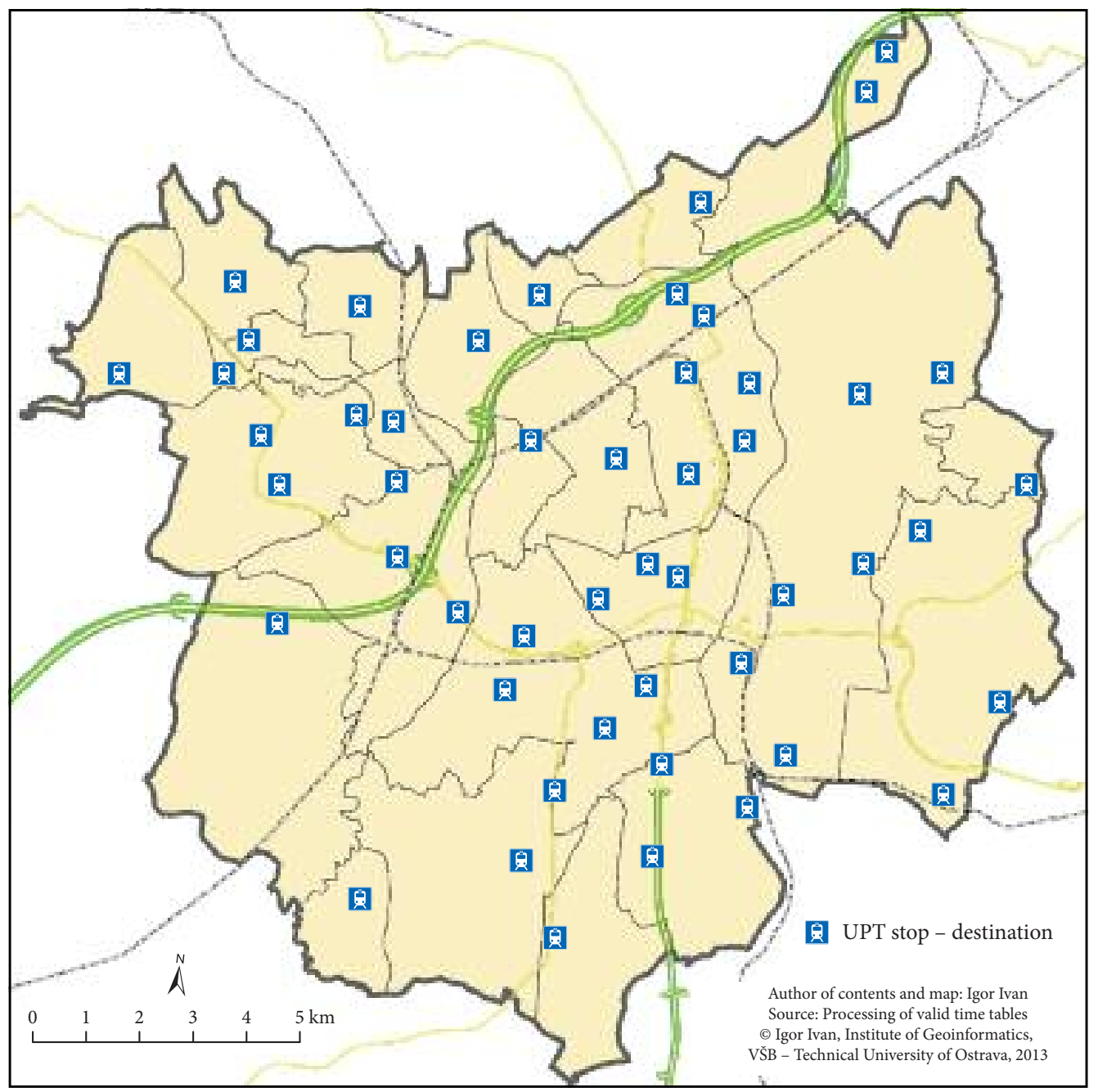

Figure 2: Randomly selected UPT stops as destinations: the case of Ostrava. 


\subsection{Interchanges: localization of interchange nodes}

After the selection of places of origin and destination, public transport connections between all combinations were searched using current timetables with arrival at $8 \mathrm{am}$. This time corresponds to the beginning of the morning shift (Mudrych 1998). All connections were searched for June 22, 2010. Overall, more than 2,500 connections (for one commuting time) were searched in timetables. These connections had to meet specific criteria used for public transport connections in the database of Public Transport Connections. This database has been developed every year since 2006 for the Integrated Information Portal of the Ministry of Labor and Social Affairs in the Czech Republic. The total duration of the journey is limited to ninety minutes, the arrival at the destination cannot be earlier than sixty minutes before the shift, the departure of the journey cannot be earlier than two hours before the shift, and total number of interchanges must be fewer than five (Ivan et al. 2013). The most suitable among all the connections meeting the criteria was selected and several attributes were recorded, including the name of the stop used for the interchange between SPT and UPT, the total travel time, and the travel time in SPT and UPT vehicles. The final list of inter-

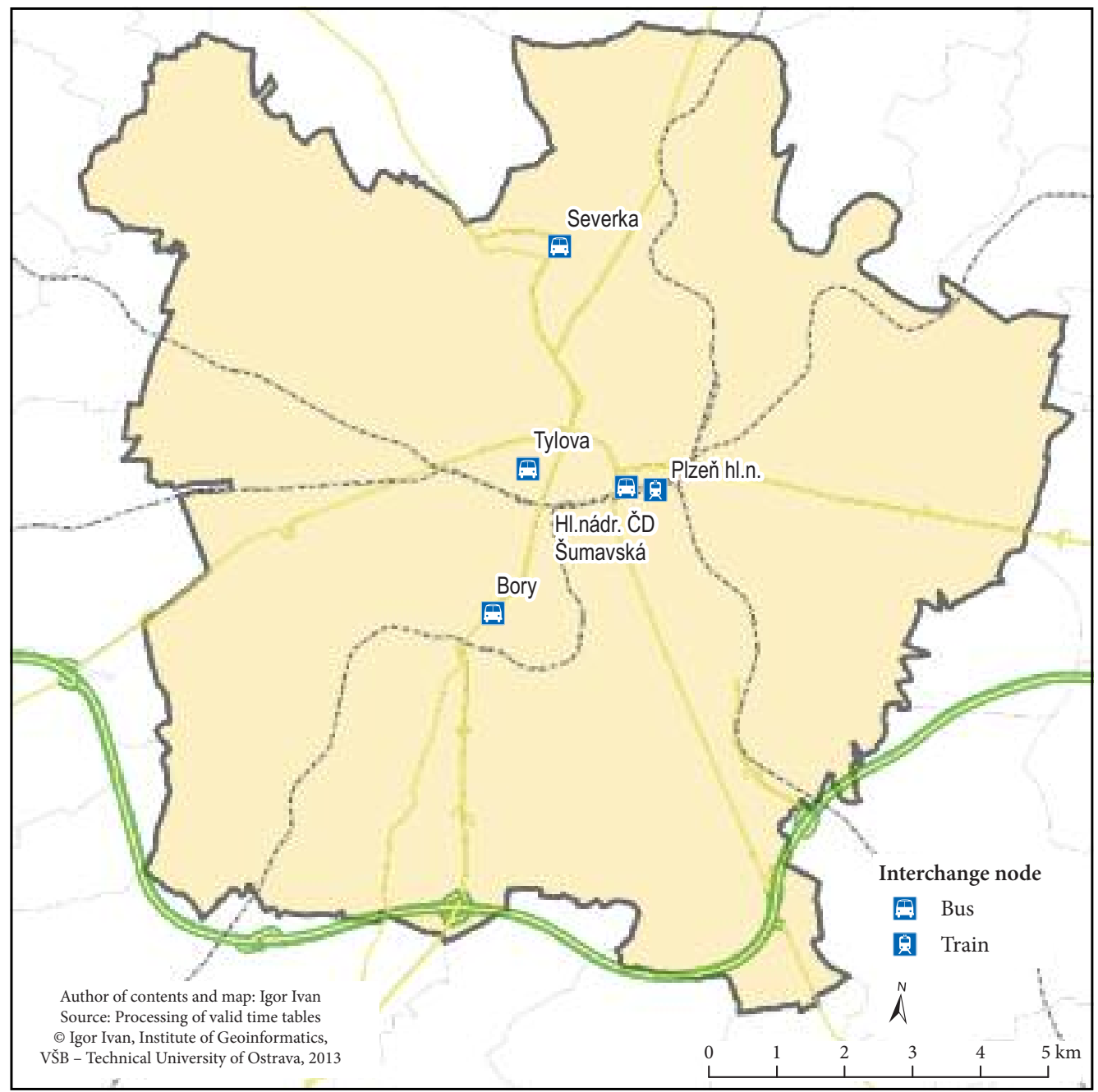

Figure 3: Final interchange nodes: the case of Pilsen. 
change nodes is based on the frequency of use. In the case of Prague, Brno, and Ostrava, each public transport stop used more than ten times is considered the interchange node. In the case of other cities, the selection of resulting interchange nodes is more individually based on local conditions without any specific limit. Altogether, seventy-seven interchange nodes were selected in these thirteen regional capitals for commuting at $8 \mathrm{am}$.

\section{Results and discussion}

Altogether, there are almost 2,500 SPT stops in these thirteen regional capitals (about 95\% of them are bus stops). The biggest number of interchange nodes is in Prague (fourteen), Ostrava (thirteen), and Brno (nine), which reflect the population of these cities. The slightly larger number of interchange nodes in Ostrava is caused by the polycentricity of this industrial city (for more, see Hruška-Tvrdý et al. 2012) compared to historical cities such as Brno and Prague. Considering the modal split, among all seventy-seven localized interchange nodes, fifty-one nodes are serviced by buses and twenty-six by trains, which makes trains more important considering the general share of bus stops among all SPT stops. The interchange nodes serviced by buses usually make up 60 to $80 \%$ of all interchange nodes in the city. Nevertheless, there are three exceptions: Prague is the only city with a prevalence of interchange nodes serviced by trains; only two interchange nodes (equally serviced by bus and train) were localized in Hradec Králové, and, finally, all four localized interchange nodes in Jihlava are serviced by buses, mainly because of the lack of a connection to the railway corridors (see Figure 4).

\subsection{Centrality of interchange nodes in regional capitals}

The centrality of the interchange node is defined as the number of interchanges per interchange node. The centrality for 8 am commuting varies from 13.2 in Pardubice and Liberec to 41.3 in Brno. The extreme situation in Brno is caused by 153 interchanges available at the main train station connected to the first railway corridor. This station is located close to the city center and services the entire region (about 60,000 travellers daily). The close UPT stop ensures accessibility to the entire city by several tram, trolleybus, and bus links, which further increases its importance. Hradec Králové is also a city with high centrality, with an average of forty interchanges per interchange node. The most used interchange node (newly developed in 2008) is serviced by bus transport and plays an important role in the regional public transport system. This new transport terminal ensures the centralization of all bus links (urban, suburban, and national) at one location (Internet). The second interchange node is in front of the main train station (a five-minute walk from Terminal HD) and ensures interconnection of the railway and urban transport system.

The situation is different in Pardubice, Liberec, and Zlín, with centrality ranging from 13 to 15 . In Liberec, the most important interchange nodes are the bus and train main stations. The official terminal (Fügnerova) was not selected by the methodology because of the small number of proposed interchanges. The results were also confirmed in 2013. This UPT stop is far from the main bus or train SPT stops. If timetables suggested using it, the walking time to the Fügnerova stop is fifteen minutes and, together with waiting times, the total out-vehicle time is about nineteen minutes (compared to ten minutes using other interchange nodes). The most often used interchange node in Pardubice according to timetables is the main train station, which provides the connection to the first and third railway corridors (twenty-three interchanges). The situation in Pardubice may change during 2014 or 2015 and the centrality of this station will increase. The surrounding area will be rebuilt and a new transport terminal will make it possible to change all modes of public transport at one location. Thus, it is possible that the future situation will be very close to the current situation in Hradec Králové. Zlín is also a city with low centrality and must rely more on bus transport. The impact of railway transport is very low, which is caused by the lack of a fast connection to the railway corridor (similar to Liberec). Zlín is connected to the corridor using the railway station in the nearby city of Otrokovice by a non-electrified single-track railway with low capacity and a frequent trolleybus line. 


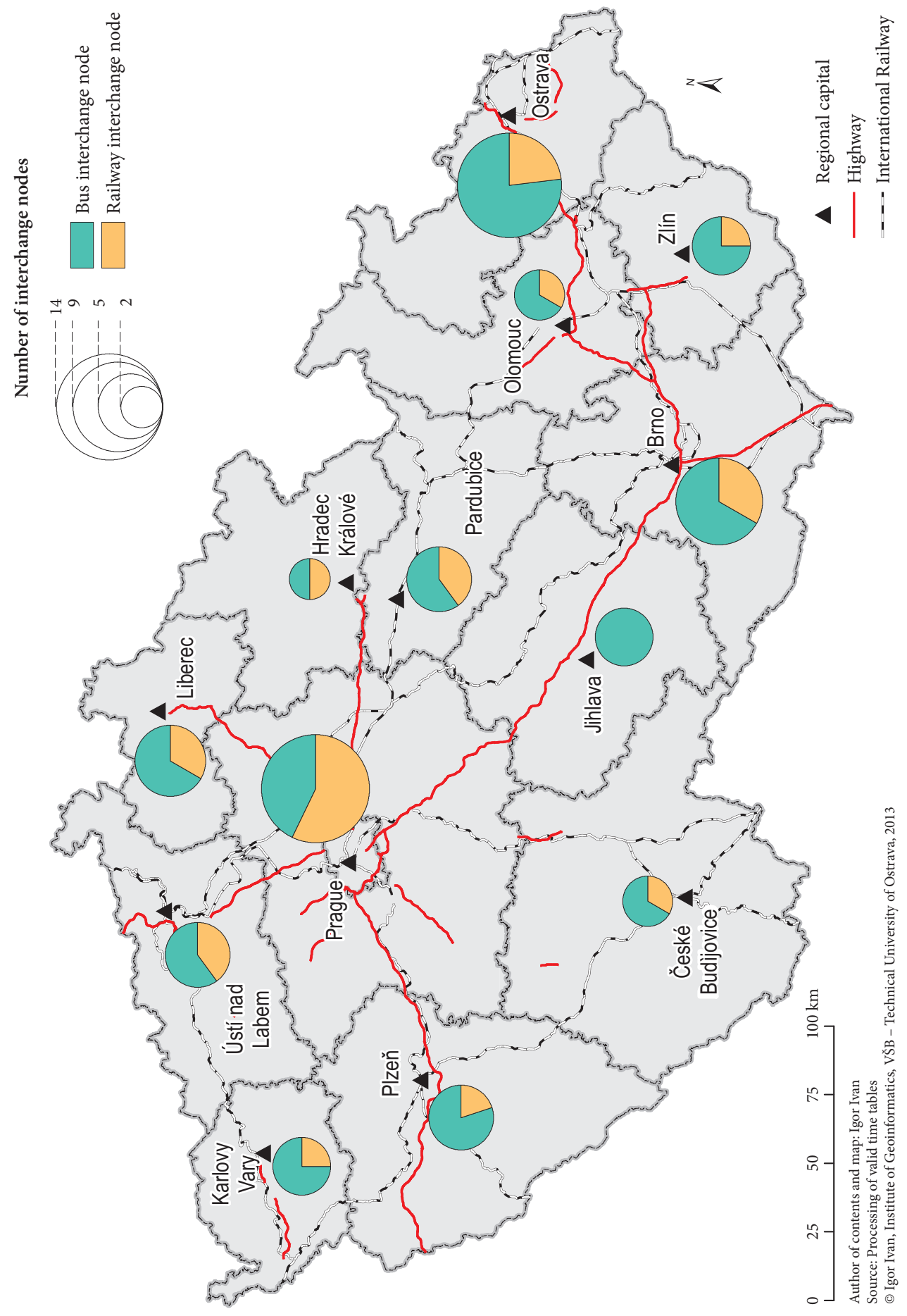




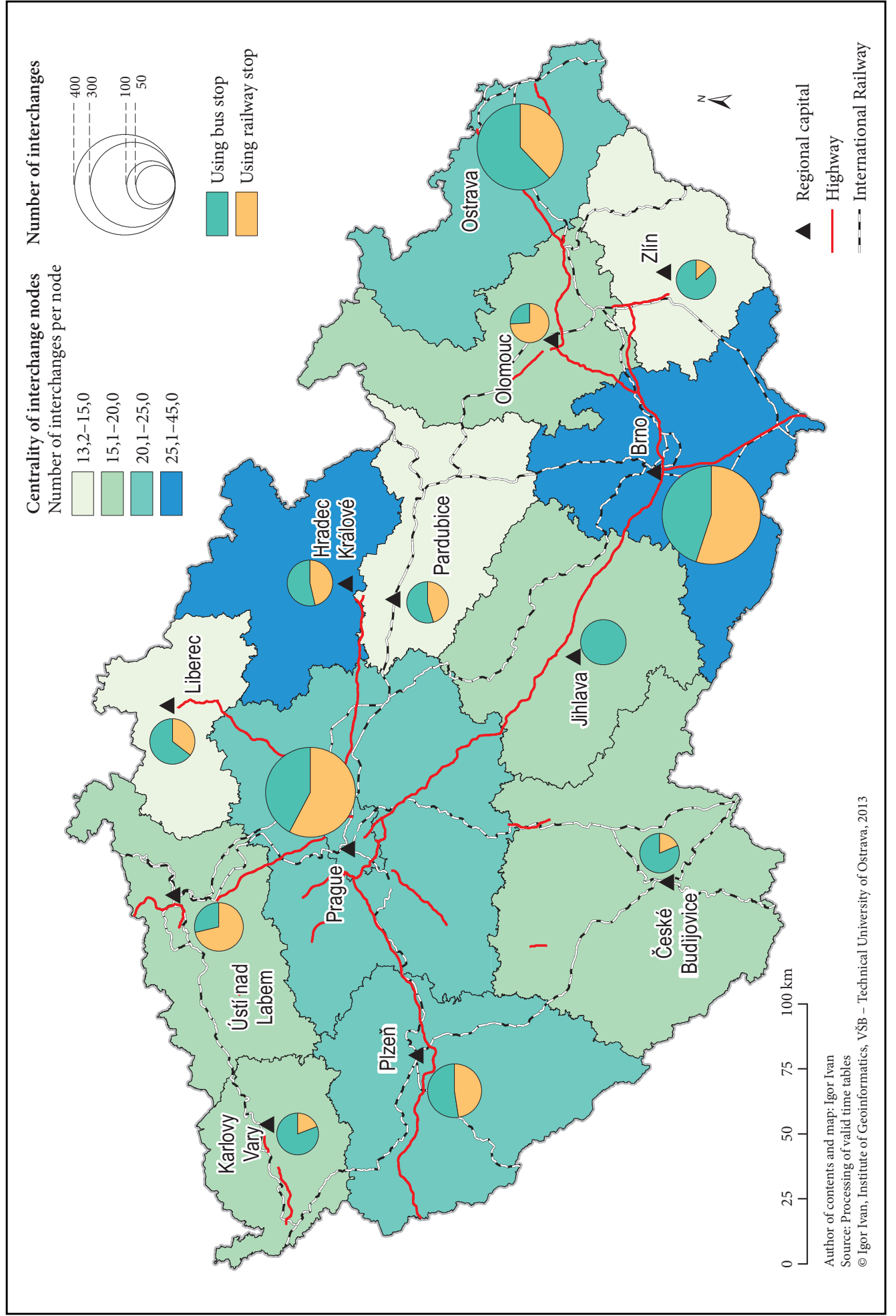


Igor Ivan, Interchange nodes between suburban and urban public transport: A case study of the Czech Republic

The city council of Zlín is aware of this limitation and has already approved the new Zlín 2020 strategy, in which the development of a new transport terminal and connection to main railway network are among the main aims.

\subsection{Orientation of regional cities to transport modes}

Cities can also be classified according to their orientation to railway or bus modes. The orientation is defined as the difference between the average number of interchanges at bus interchange nodes and average number of interchanges at railway interchange nodes. If the final ratio is -10 or less, the interchange node is considered railway-oriented and, analogously, if the final ratio is above 9 the interchange node is bus-oriented. Brno, Pilsen, Olomouc, Ustí nad Labem, and Ostrava are the cities with the highest dependence on trains (in descending order). This is mainly due to the connection to the railway corridor and the dominant role of main railway station close to UPT stops. The city absolutely most dependent on railway transport is Brno, where $55 \%$ of all interchanges are made at three localized railway interchange nodes $(33 \%$ of all nodes) and the average number of interchanges at railway stations is almost 2.5 times higher than in case of bus nodes. On the other hand, Jihlava, České Budějovice, and Zlín are dependent mainly on bus transport. This is mainly due to their peripheral position in the railway network hierarchy (although České Budejovice is connected to the fourth railway corridor) and the dominant role of the bus station. The situation in Jihlava may change during the coming years, when the new transport terminal will be developed next to the existing railway station. The third group consists of five cities with a similar average number of interchanges at the interchange node of both modes.

\subsection{Time stability of interchange nodes}

The results presented above describe the 8 am commuting situation, but the selected interchange nodes may vary for different times. To analyze the spatio-temporal stability of interchange nodes, the interchange nodes have also been localized for $2 \mathrm{pm}$ and $10 \mathrm{pm}$ as the beginnings of the afternoon and night shifts. The three largest cities (Prague, Brno, and Ostrava) were selected for the case study.

Generally, the number of significant interchange nodes decreased and the use of the most important nodes increased, reflecting the principle of elitism and increase of centrality. Based on 570 connections searched, fourteen interchange nodes were selected in Prague for 8 am commuting. This number decreased to eleven for commuting to the afternoon shift or twelve for commuting to the night shift. This development is quite unique among the cities analyzed. The railway station (Masaryk station) remained the most important for all commuting times. In case of all times analyzed, one bus stop (Černý Most or Opatov) reached a similar frequency of use as the Masaryk station. Prague is a typical city with a large number of interchange nodes with similar use without one or two significant central interchange nodes. No interchange node is as central as in the case of Brno or Ostrava, with a share above $20 \%$ of all changes made at one stop.

In Brno, nine and six interchange nodes were localized for commuting to the afternoon and night shift. The main role of the central railway station also remains unchanged for other commuting times and the frequency of its use increased to $44.2 \%$ for $10 \mathrm{pm}$ commuting. This increasing centrality causes a decreasing use of all other important interchange nodes, mainly bus stops. Three bus interchange nodes provide $25 \%$ frequency of use for 8 am commuting, but only one of these stops plays the role of an interchange node with a frequency of about $3 \%$ for 10 pm commuting.

The Svinov railway station and Svinov Mosty bus stop remain the most important interchange nodes in Ostrava, but they switch positions for night shift commuting. They service the connections from the western and southern parts of the region. In the case of 8 am commuting, more than $25 \%$ of interchanges are made at these two nodes and this share increases to $33 \%$ of all interchanges for $10 \mathrm{pm}$ commuting. The other important interchange node is the main bus station in the city center, with an increasing frequency of use from $6 \%$ to almost $10 \%$. This stop serves the heavily populated eastern part of the region. However, the situation may change during the coming years because the city council plans to develop four main interchange nodes. This analysis has located two of them so far. 

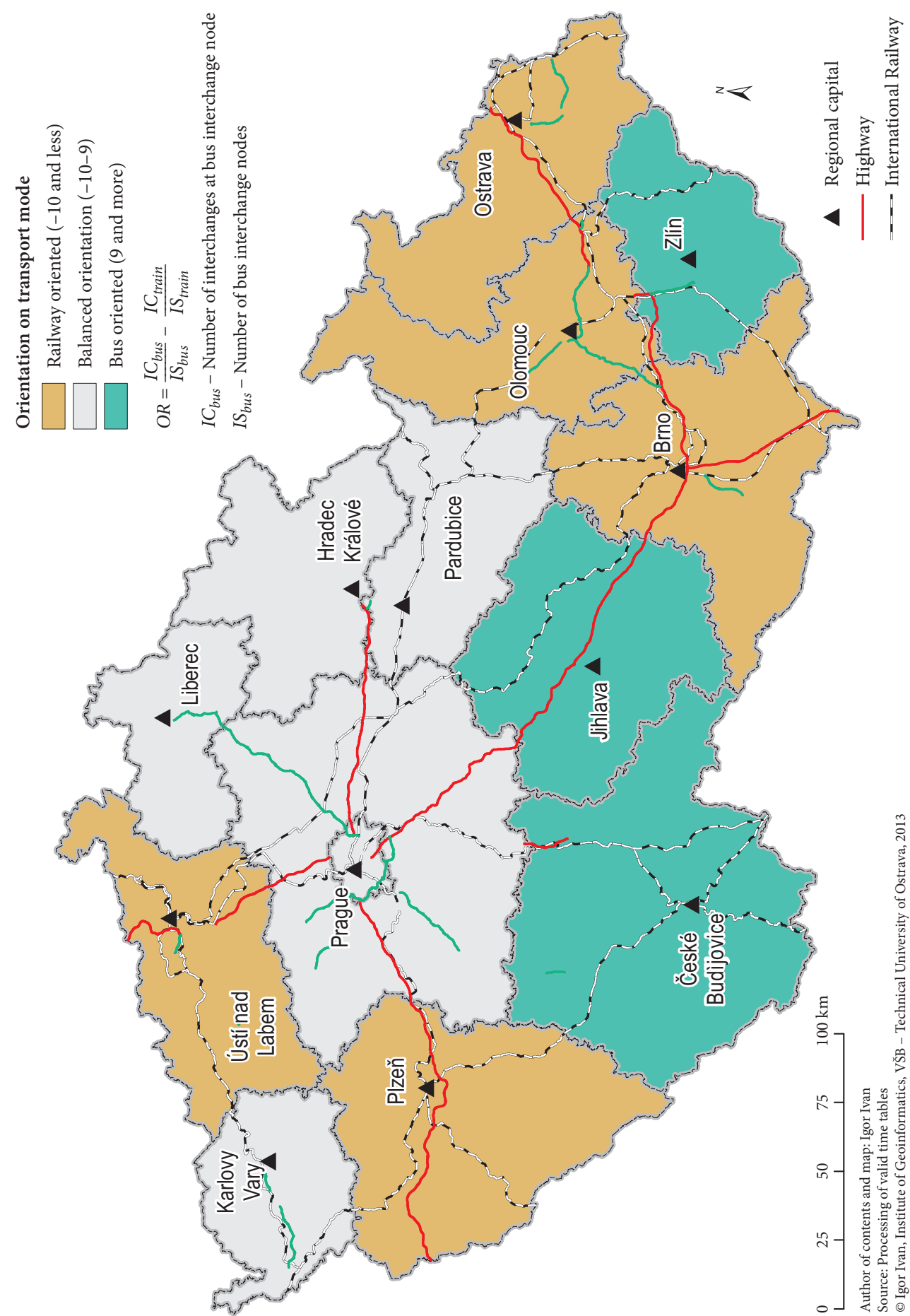


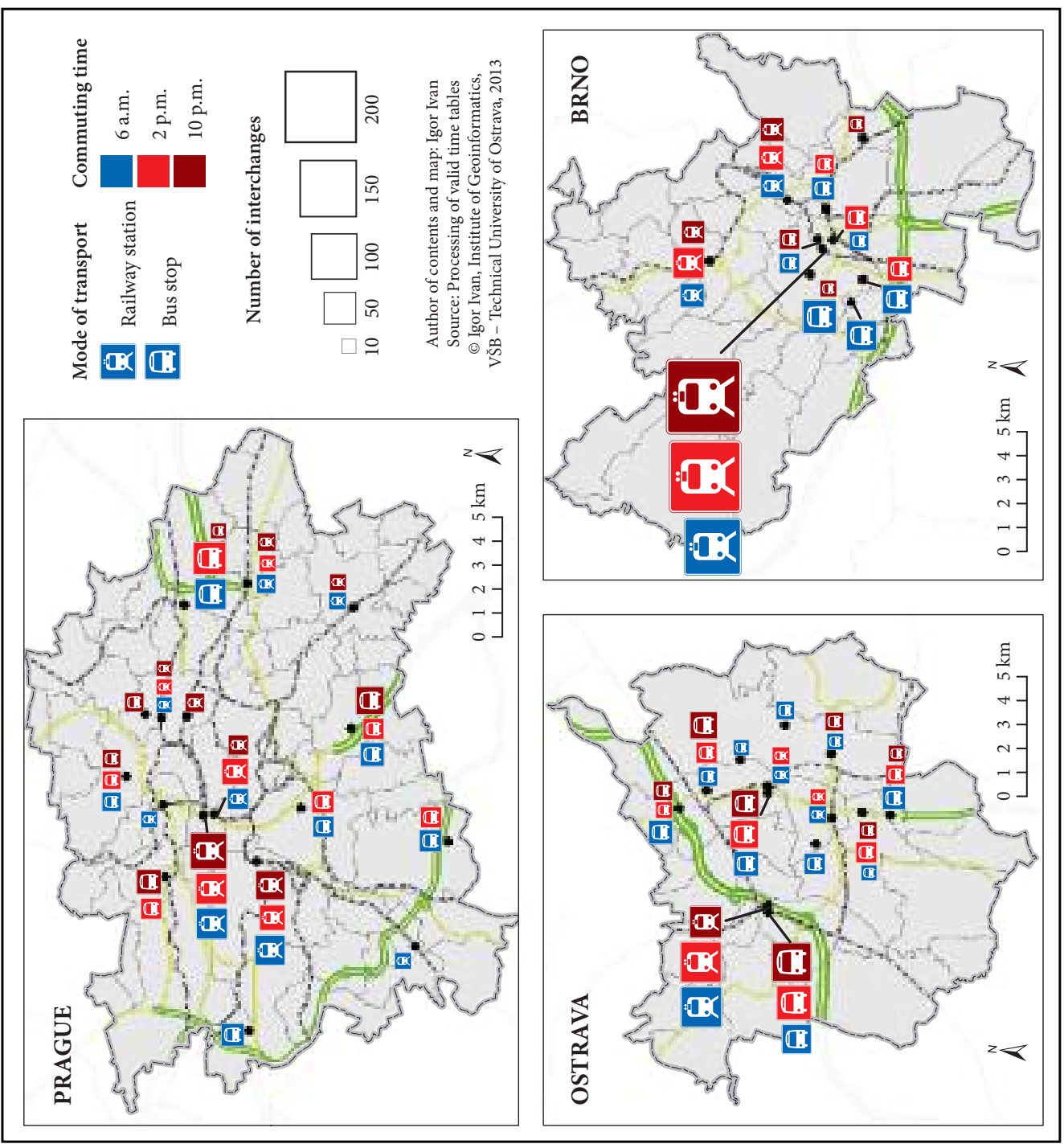

Figure 7: Time stability of interchange nodes in Prague, Brno, and Ostrava.

\section{Conclusion}

Changing vehicles or transport modes is a very current topic mainly due to budget cuts in support for public transport. This is why city councils, regional government, and the national government in the Czech Republic must economize public transport connections. This leads to decreasing the number of parallel links and to increasing the number of interchanges to reach final destinations. This paper introduced a methodology for localizing theoretical interchange nodes in thirteen regional capitals in the Czech Republic. Based on current timetables, over 2,500 public transport connections were evaluated and seventy-seven interchange nodes for 8 am commuting were localized. Generally, it is possible to divide regional capitals into three categories according to dominance of railway stops (five regional capitals) or bus stops (three regional capitals) for interchange from SPT to UPT. The third group consists of capitals with a similar use of both types 
of transport (five capitals). Similarly, the centrality of interchanges within these cities can be evaluated. Many cities have their own specific features, and two main factors influencing interchanges in the city can be selected. First, the existence of a connection to the railway corridor increases the importance of the main railway station. Second, cities with already existing or recently developed transport terminals interconnecting SPT and UPT are unique in the centrality of their interchanges (the cases of Hradec Králové and Brno). The situation could change in the future because in several capitals there are projects to develop new modern transport terminals (the cases of Zlín, Jihlava and Pardubice).

The time stability of these interchange nodes for $2 \mathrm{pm}$ and $10 \mathrm{pm}$ commuting was investigated based on the example of three regional capitals (Prague, Brno, and Ostrava). The results tend to show similar figures related to principle of elitism. The number of significant interchange nodes decreased, whereas the frequency of use of some of the most significant interchange nodes increased. There is also a tendency for an increasing number of connections that did not meet the criteria of the methodology presented. New interchange nodes (less important due to their frequency of use) appeared rarely and with only a small frequency of use.

ACKNOWLEDGEMENTS: The research was supported by the Czech Science Foundation, project no. 14-26831S.

\section{References}

Bole, D., Gabrovec, M., Nared, J., Razpotnik Visković, N. R. 2012: Integrated planning of public passenger transport between the city and the region: the case of Ljubljana. Acta geographica Slovenica 52-1. DOI: http://dx.doi.org/10.3986/AGS52106.

GUIDE 1999: Group for urban interchanges development and evaluation, European Commission, the fourth framework research and technological development programme. Brussels.

Guo, Z., Wilson, N. H. M. 2011: Assessing the cost of transfer inconvenience in public transport systems: A case study of the London Underground. Transportation research A: policy and practice 45-2. DOI: http://dx.doi.org/10.1016/j.tra.2010.11.002

Hine, J., Scott, J. 2000: Seamless, accessible travel: users' views of the public transport journey and interchange. Transport policy 7-3. DOI: http://dx.doi.org/10.1016/S0967-070X(00)00022-6

Hruška-Tvrdý, L., Kukuliac, P., Horak, J., Ivan, I., Foldynova, I. 2012: Socioeconomic atlas of Ostrava. $15^{\text {th }}$ International colloquium on regional sciences. Brno.

Internet: http://www.dpmhk.cz/cs/terminal-hromadne-dopravy-hradec-kralove/o-terminalu (15.2.2013).

Ivan, I. 2010: Docházka na zastávku a její vliv na dojíždkku do zaměstnání. Geografie 115-4.

Ivan, I., Horák, J., Fojtík, D., Inspektor, T. 2013: Evaluation of public transport accessibility at municipality level in the Czech Republic. SGEM 2013: $13^{\text {th }}$ international multidisciplinary scientific geoconference on informatics, geoinformatics and remote sensing. DOI: http://dx.doi.org/10.5593/SGEM2013/ BB2.V1/S08.030

Mudrych, P. 1998: Morning peak hours as a base for geographical studies in the hinterland of Czech towns. Geografie 103-4.

Stokes, G. 1994: The role of public transport interchange in improving public transport. Proceedings of seminar E, 22nd PTRC European transport forum. Warwick.

van Vugt, M., van Lange, P. A. M., Meertens, R. M. 1996: Commuting by car or public transportation? A social dilemma analysis of travel mode judgements. European journal of social psychology 26-3. DOI: http://dx.doi.org/10.1002/(SICI)1099-0992(199605)26:3<373::AID-EJSP760>3.0.CO;2-1

Vande Walle, S., Steenberghen, T. 2006: Space and time related determinants of public transport use in trip chains. Transportation research part A: policy and practice 40-2. DOI: http://dx.doi.org/10.1016/ j.tra.2005.05.001

Wardman, M., Hine, J. P. 2000: Costs of interchange: a review of the literature. Leeds.

Wardman, M., Hine, J. P., Stradling, S. 2001: Interchange and travel choice. Leeds. 
